\title{
School libraries, information gap and social inclusion in Papua New Guinea - Making it happen.
}

\author{
Marlene Filippi \\ Schools Adviser \\ International Education Agency \\ Papua New Guinea
}

School libraries, just like the school community, do reflect the social environment in which they operate. This is the story of the emergence of one such library, within Papua New Guinea and its development through the assistance of AUSAID. It looks at an idea - Resource Based Learning which has enabled the local community to take ownership of a resource centre which will now be able to provide a true teaching/learning environment for all of the community.

It is more than a collection of books! It has the beginnings of a vibrant active resource for the whole community.

\section{Setting the Scene}

Last year I was fortunate to be able to deliver through the Education Capacity Building Program an AUSAID funded project to a small cluster of schools in Kavieng which is in the New Ireland Province of Papua New Guinea. The Education Capacity Building Program is a 10 year partnership between the Australian and Papua New Guinean Governments to support the National Department of Education to achieve the outcomes of the National Education Plan for 2005 - 2014. This plan identifies outcomes for education in Papua New Guinea and how these will be achieved over the next 10 years. The beginning of this plan saw the establishment of four Integrated District Management Projects, one of which was the establishment of a Resource Based Learning Environment at Kaselok Community School.

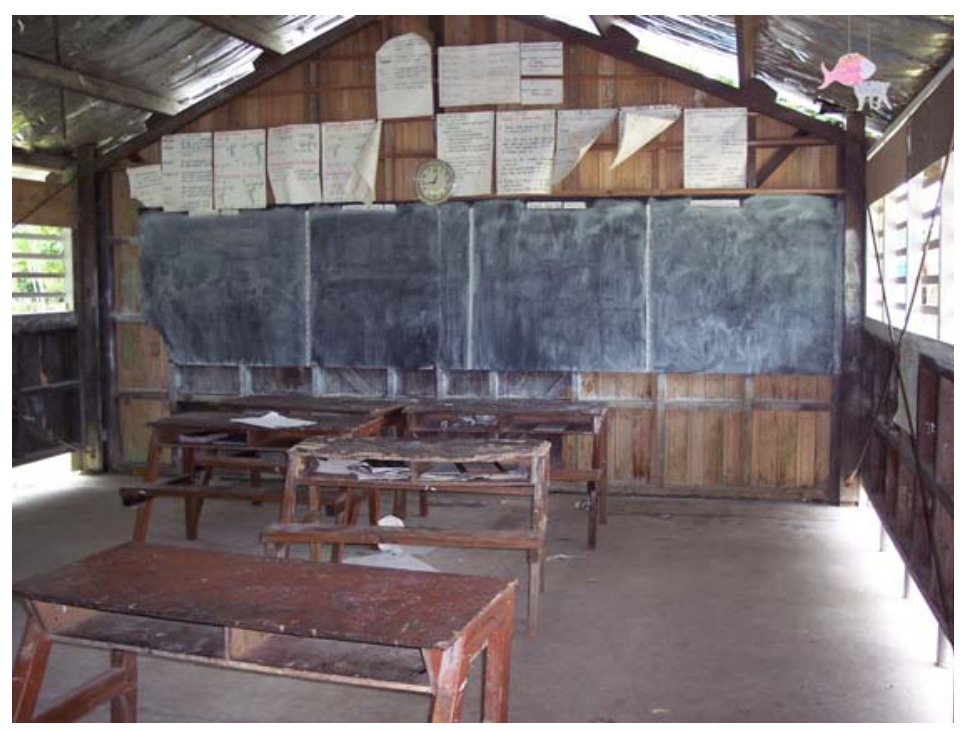

Kaselok Primary School 
Marlene Filippi

To complete this project I was seconded from my employer, the International Education Agency, the largest provider of private education in Papua New Guinea and my role as Schools Adviser to the schools of the IEA.

The International Education Agency of PNG Ltd (IEA) is a registered provider of private education and training in Papua New Guinea and is registered under the PNG Companies Act 1997. It currently owns 19 schools across PNG and manages one on behalf of the mining company, Ok Tedi in Tabubil.

IEA schools have Permitted Status with the PNG National Department of Education (NDOE) to educate students from preschool to Higher School Certificate (HSC) Level. The IEA High Schools in Port Moresby and Lae are also registered with overseas education systems to offer various international certificate courses to HSC level. These include the International Baccalaureate and the Australian Capital Territory HSC.

The IEA College of TAFE and a number of IEA schools are also registered with the National Training Council of PNG to conduct training for school leavers.

The IEA has partnership agreements with overseas institutions to provide technical training and academic programs within PNG. Partnership agreements currently being operated include several TAFE Colleges in Australia, the Queensland University of Technology and Southern Cross University.

The IEA was formed by the PNG National Government at Independence in 1975 to administer the many Primary-A schools that had been set up by the pre-independence administration to educate the children of expatriate families living and working in PNG. The IEA at this time was part of the National Department of Education and governed by The International School's Board via a sub-section of the Education Act.

In 1987 the IEA was set up as a private not-for-profit company limited by guarantee and governed by the IEA Board of Directors who represented the member school associations. The International School's Board remained an important link between the IEA and the National Department of Education.

Largely as a result of the requirements of the new PNG Companies ACT 1997, the IEA was re-constituted and registered as a private company limited by share in 1998 . The shareholders of the IEA Company of today are the Incorporated Associations of the schools owned by the IEA. The chairpersons of the shareholder school Associations elect the Board of Directors at the Annual General Meeting.

The IEA employs approximately 350 professional teachers, about 50 of whom are expatriates. The IEA also employs over 600 ancillary staff across PNG in various semiprofessional and technical capacities.

Up until 1991, the IEA teaching force of over 300 consisted entirely of expatriates. In 1992 the IEA embarked on a localisation program. This program began with the localisation of the entire school staff at Coronation College in Lae and Gordon International School in Port Moresby. The pace of the localisation has accelerated since this initial phase and now, in addition to the $75 \%$ PNG teacher workforce, more than $60 \%$ percent of the schools have Papua New Guinean Principals. The IEA is totally dependent on school fee income to run the schools. 
This localisation program involved a commitment to professional development to support the Papua New Guinean teachers new to IEA and its very different educational philosophy and environment. The schools were initially led and managed by expatriate principals and the professional development programs were facilitated by specially recruited overseas trainers. The professional development was enhanced by supporting the new Papua New Guinean Teachers to complete Bachelor of Education degrees at Queensland University of Technology and Southern Cross University in New South Wales.

The ongoing professional support for IEA teachers is now supplied by the IEA Centre for Professional Development (CPD). The CPD, of which I am a part, provides support for academic programs provided by overseas universities as well as a range of local workshops and school-based training covering a wide range of educational and management areas. It was with this support that I was able to become involved in the Resource Based Learning Project.

The Integrated District Management Project which was the project under which this workshop took place, was a plan to work at all levels to strengthen links between the national, provincial, district and school levels to improve service delivery for the benefit of all children. This encompassed many areas in that it envisaged an improvement in the areas of planning, communication, technology, establishment of centres for training and development and a strengthening of school-community partnerships. The Kaselok project was this and more.

\section{What happened next?}

The Kaselok Resource Centre, which is situated 20 minutes from Kavieng in far north east Papua New Guinea, was first established in 2000 as part of an AUSAID project. The building was relatively new and in good condition and most of the resources on the shelves had come from donations through Rotary in Australia, although power was dependent on a generator.

As this was part of the Education Capacity Building Program and an Integrated District Management Project there was a great deal of negotiation before the project was undertaken. The community had met with the Education Officer and discussed what they saw as being their resource centre of the future. Now, the object was to find someone who could put this plan into action. Terms of Reference were raised and tenders were submitted. I was successful in my application.

My prior involvement with the community, before the project, was reliant on verbal reports from the supervising officer and the local education officer. I had never been to Kavieng and did not know what to expect, but Kavieng is a beautiful place. It was idyllic, just like living in paradise. I lived on an island, Nusa Island Resort and went to work on a boat and then travelled in a car. The dining room at the Resort had beach sand as the floor and no windows or door, openings with just half walls and long bench type seating. All of the buildings were made from bush materials.

Kavieng Accommodation

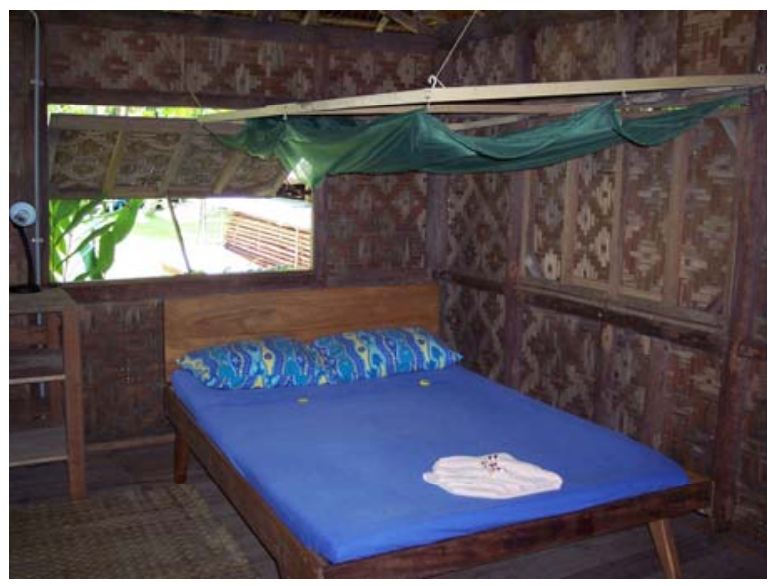


I was to work with teachers who had on very few occasions worked with an expatriate. This was an experience for both the teachers and me. It took time to establish a relationship of trust, as Papua New Guineans, although extremely friendly, are not normally great conversationalists, until they know and feel comfortable with you. Introducing myself to the group, with some background detail, eased the situation a little and when I explained that they were the participants of a pilot program they were very receptive. However, a feeling of trust still needed to be developed. Papua New Guinean teachers are like sea sponges in that they have the desire to absorb as much learning as is available to them. Time is never a problem and these teachers had elected to sacrifice their holidays to be a part of this project - such is their love of learning.

Before any real teaching could happen it was necessary to impart some basic knowledge - none of the teachers had a library qualification and some had never been into a library. The first visit for some teachers to the resource centre was like inviting children into a shop full of sweet delights. I asked the teachers to first, browse and look at what was on the shelves and then I would ask them some questions. I gave them no more specific directions. This activity took more than one hour, as one by one these teachers took books from the shelves and started to read. It was as though the world had suddenly opened up, some were reading fiction picture books and some were reading non fiction, but all were reading. This is a humbling experience watching adults who have a thirst for knowledge and an appreciation of literature who cannot get enough books to read. If these people are teachers imagine the impact this resource centre will have on the students. My question of the teachers was what had they noticed and what did they see? Some had noticed that the books were separated into sections.

The next task involved a very quick introduction to Dewey and the way in which the resources would be shelved. Classification was the aim. All the books (approximately 1000) were removed from the shelves and the teachers were divided into groups to sort through the resources. The first step was dividing the books into fiction and non-fiction. Step 2 was to then divide the fiction books into junior fiction and senior fiction. This was not a quick task as many teachers took this opportunity to read the books which they were handling. It was unfortunate that this workshop was restricted to the duration of one week, as there was much to be taught and learnt. Discussion was held as to how to identify these resources and make a decision as to its location. Once again the process was time consuming as many teachers stopped to read. Picture books were a great favourite! The resulting activity did however; result in a great deal of discussion as to the guidelines for classifying a resource and reading the books served to give teachers more insight to the decision making of why should a resource be placed in a particular section. This then had to be another very quick lesson in the determination of the placement of the resource. One of the questions I asked the teachers was: where would you look to find this information?

Having divided the books into fiction, junior and senior and non-fiction, the next task was to then sort the books according to Dewey. It should also be mentioned that the building which houses these resources is not air-conditioned and the windows are very small. Kavieng, at any time of the year is quite hot so it was not possible to spend a great deal of time in this environment. This necessitated completing the task over several sessions, before everyone became a large puddle of perspiration.

\section{Resource Based Learning}

Resource-based learning was going to be the method by which these teachers could learn to utilise the resources already on hand and how to use the new resources which would 
Marlene Filippi

soon arrive. This was a new term and all of the participating teachers were unfamiliar with its meaning. Resources to these teachers meant paper, books and those treasured objects that live in a library. These can range from books, journals, newspapers, multi-media, Web, community and people. I needed to show the teachers of Kavieng how to use the resources which they had, use the people resources in the community, make the best of what was available, as well as give them the skills they would need to use the new resources which would be purchased as part of this project.

Resource-based learning is the achievement of both subject and information literacy objectives through exposure to and practise with a large variety of resources. Students become active learners as they use a wide range of materials to investigate subject material prescribed within their classroom curriculum. Teachers and librarians, if available, become motivators and facilitators in the learning process. They are the personnel who set the tasks which drive the students to seek information and become creative problem-solvers.

Two essential features of resource-based learning are its flexibility in terms of adaptability to different learning styles and subject areas, and its promotion of student autonomy. Students develop information literacy skills through formal and informal practice with tasks requiring information from a variety of resources. Use of multi-media teaching aids by the teacher does not qualify as resource-based learning. It is students who must work with resources to learn about topics through their experience of problem solving as they piece together information strands to formulate meaningful knowledge about a subject. Increased autonomy results when students have opportunities to identify what they know about a topic and what they need to learn; where to look for information; how to record information as notes; how to evaluate information; and how to assess their success with the information-seeking process.

Resource-based learning involves active participation with multiple resources (books, journals, newspapers, multi-media, Web, community, people) where students are motivated to learn about a topic by trying to find information on it in as many ways and places as possible. Encouraging students to direct their information pursuits adds to the sense of ownership of learning, self-confidence, and reinforcement of information-gathering patterns when an information goal is achieved. Resource-based learning is student- centred and operates on the premise that students learn by doing and making meaning as individuals.

Resource based programs guide students to develop the skills to:

- develop the capacity to recognise a need for information, to know how and where to find it from a range of sources, and how to select, organise and communicate it to others;

- acquire the skills required to analyse, interpret, systhesise and organise information as well as the language and communication skills of reading, writing, viewing, speaking and listening;

- develop as critical thinkers and creative problem solvers extend their cultural understandings and their information competencies in increasingly complex contexts, using a range of information sources, formats and technologies as an integral part of their learning;

- use resources including literature, to further their personal growth.

The knowledge, understandings and the necessary skills for learning are introduced developmentally and incrementally. In developing these abilities, teachers and teacher librarians work cooperatively to combine knowledge of the curriculum, knowledge of 
Marlene Filippi

individual students' needs and competencies and knowledge of information sources, resources and technologies. (Australian School Library Association and Australian Library and Information Association, Learning for the future: developing information services in Australian schools, Curriculum Corporation, 1993)

Resource based learning is a tool that empowers students to take control of their own learning and it became the tool by which local teachers became more aware of the resources within their own community. Teachers were taught that RBL fosters the development of individual students by accommodating their varied interests, experiences, learning styles, needs and ability levels and that the teacher is the facilitator who is able to guide the students in their self discovery journey. This was a huge learning curve for teachers who are accustomed to standing in front of a class and delivering information. Most of the teachers found this concept very difficult - they couldn't understand that to be a facilitator you don't have to know all the answers. They were so used to only teaching what they knew and understood and felt if they did not have all the answers then they had failed in their position of a teacher. They expected that they should be experts rather than teachers with expertise. This was part of the aura that surrounded teachers - they are the beings that impart the knowledge which they have acquired. This is a reflection of the Papua New Guinean culture in that elders are to be respected. This was the challenge in designing a package which would be meaningful to the teachers who were about to discover Resource Based Learning and learn how to utilise this with their own students and teach them that they did not have to have all the answers all the time.

I was able to effectively utilise the resources which were found within the extensive school grounds. Most of the teachers admitted that they had taken the environment for granted and not thought of it as a teaching tool. The teachers and I walked around the grounds and looked at the environment but through a child's eyes and asked many questions, e.g. why does moss grow on the shady side of the tree? Why does the coconut fall from the tree? The teachers found this very difficult as many did not know the answers and felt they were inadequate as teachers. It was necessary to explain that teachers were facilitators who would provide the necessary resources so that students could discover the answers for themselves.

Making Resources at Kaselok Primary School, in the outdoor learning area built for the workshop. Classrooms were too hot!

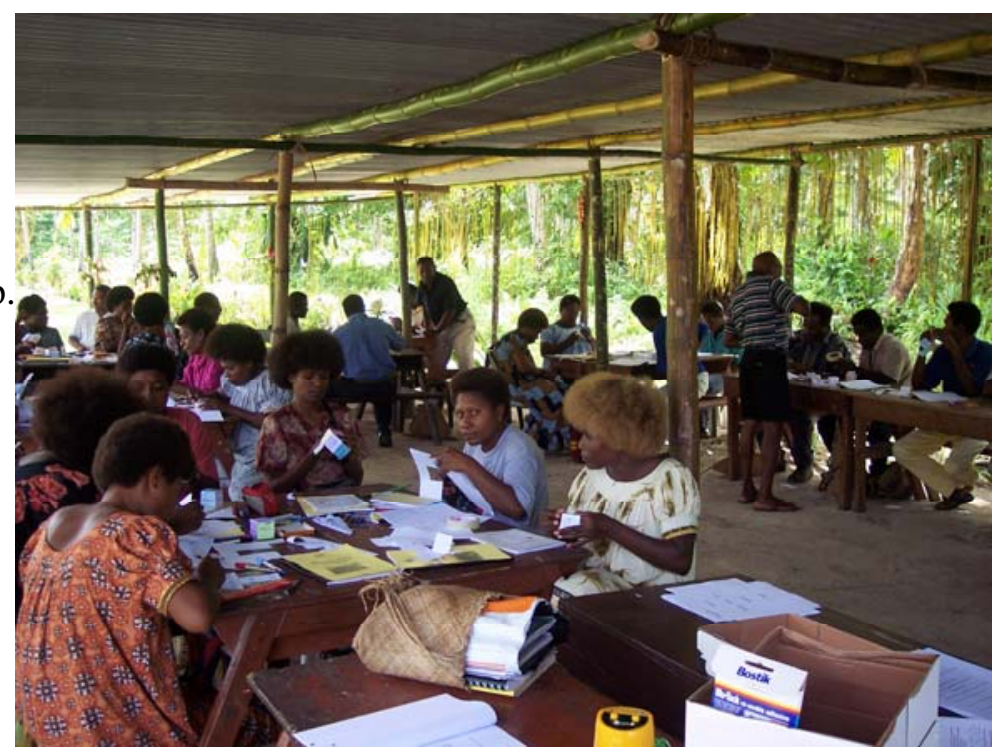


Marlene Filippi

Resource based learning has all the components necessary to take this resource centre and use it to encourage learning on a topic through the students' interaction with an effective use of a wide range of print, non print and human resources. It will also enable information literacy skills to be taught through multiple curriculum areas.

Resource based learning promotes the development of thinking skills such as problem solving, reasoning and critical evaluation and skills for accessing, evaluating, using, and applying information, ensuring that students meet the outcomes for information literacy and these were the skills that the teachers first needed to learn.

Resource based learning by undertaking research projects enables the construction of meaning through active participation with information resources and promotes acquisition of effective information skills through conceptual awareness of the nature of information and its diversity. Who would have thought that catching fish could be such a meaningful and useful example when trying to explain the information process?

\section{Interpreting Information Skills in Real Terms}

Defining, Locating, Selecting, Organising, Presenting, Assessing - the six steps required to achieve information literacy. Considering that the group of teachers with whom I worked had limited experiences with libraries it was important that the information process was put into real terms.

I used the example of the fisherman who wants to catch a lot of fish. Coastal Papua New Guineans love to fish and fish forms the staple of their diet, so this was very real to all of the participants. It was time to introduce the terms, defining, locating, selecting, organising, presenting and assessing. I did this in the following manner:

Defining: The project is: "I want to catch a lot of fish."

Locating: Now find the resources which will help to catch a lot of fish, e.g. a boat, information about the weather and the tides (from the Fisheries College) talking to the fisherman from the village,(using local community members) who can tell you where he caught most of the fish yesterday.

Selecting: Determine which of these resources is most reliable - will it be the Fisheries College or the fisherman from the village - or are they both equally valuable? (This is choosing the most reliable and accurate resources to supply the information necessary to catch a lot of fish)

Organising: Looking at all the information available and arranging it to support 'I want to catch a lot of fish.(Selecting and reviewing the best information and getting ready to go fishing, taking note of the best day according to the tides, collecting fishing reels, bait) Presenting: This is showing/sharing the result of the project - I want to catch a lot of fish this could be coming back with a boat load of fish and showing everyone at the village Assessing: Was the project achieved? Many fish were caught so the fisherman will go back to the same place and fish when the tide is at its best.

This was an extremely successful presentation of the 6 processes in the developing of information skills and as it was in real terms, it was easily understood. It did not however, start and finish with fishing. It related well to outcomes based learning and other examples were put into practice. For example, each day a group of local women prepared a mumu for lunch.

This is the cooking of all food, e.g. taro, fish, crab, pumpkin, tapioca and sweet potato wrapped in banana leaves, being put into the ground on hot embers from the fire. We established, as a group, that maybe the local women were trying to fatten us up so we 
interpreted this aim through the processes of, defining, locating, selecting, organising, presenting and assessing. This became a fun interpretation of the process and was reinforced on the final day when one of the participating teachers sat on a stool which broke. It was determined then that the cooks had achieved their outcome and this accident had been the assessment phase.

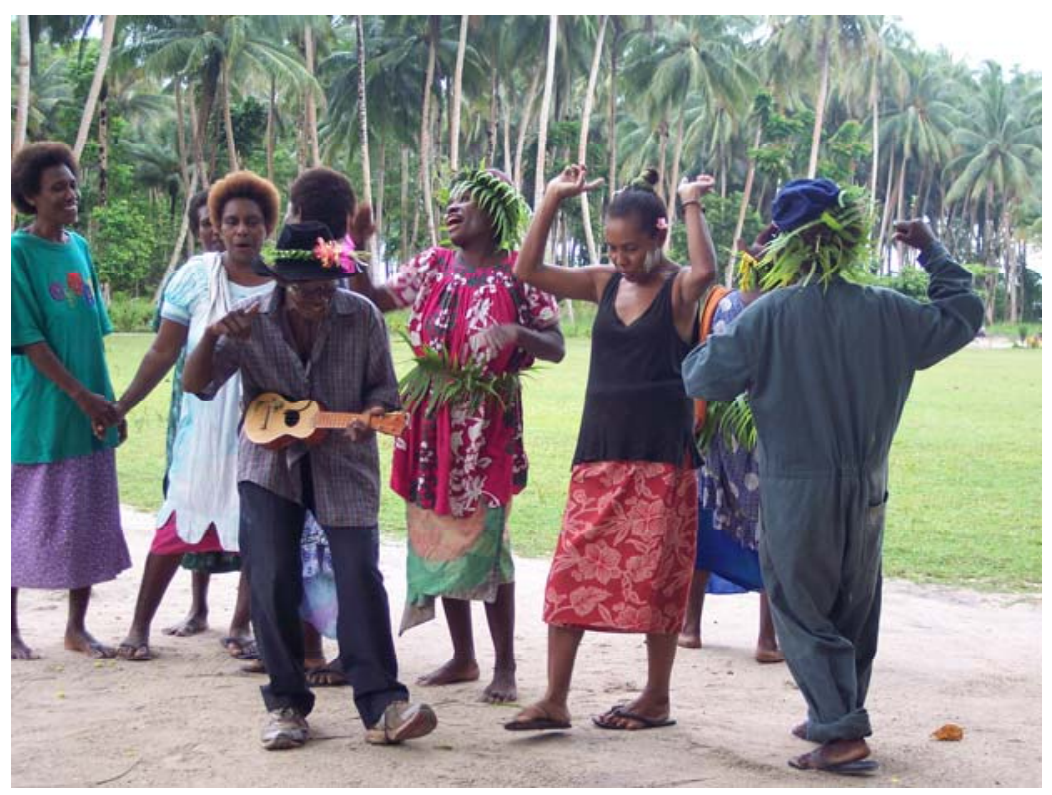

The sing sing group of the local cooks who fed us so well each day.

\section{Involving the Community}

The success of this venture/pilot program is now very much dependent upon the support of both the teachers and the community. I met with the Board of Management on the Saturday after the workshop and we discussed the future of the resource centre. This was the time that my pidgin improved dramatically as most of the Board Members spoke very little English. A plan was drawn up after much discussion and another meal of mumu and fruit. The Board welcomed this opportunity to have additional funding for the resource centre and they very much desired that the community would have access to this meeting place. There was and is a great deal of concern amongst the elders of the village that many of the traditional ways are being lost and this would be an opportunity for old and new to enhance the learning for all. An example of this is the use of 2 sewing machines which were already in the building and it was agreed that sourcing some simple Mary Blouse patterns would enable the community to help the younger women to learn how to sew some attractive clothing. It was also suggested that simple cookbooks be purchased to encourage women to try to cook different things. With the advent of western ways many women are neither cooking the traditional way nor cooking a nutritious meal using western ingredients. This is one of the many problems now facing Papua New Guineans whose staple diet has become rice and tinned or fresh fish and with even less nourishment 2 minute noodles which are cheap and easy to prepare. The traditional way of cooking a mumu takes many hours and to prepare a lunch the women need to rise at 3am to prepare the fire so that the embers will have reached the right temperature by $5 \mathrm{am}$ and the meal will then be ready by midday. It was through the discussion with the board that decisions were made as to the resources which would be purchased to support this centre.

In addition a list of personnel was made of people within the community who would be available to come in and work with both students and adults. With the increase in AIDS 
Marlene Filippi

awareness the centre would be made available to the local visiting Health Sisters for meetings with the community. As part of the resource package being supplied through AUSAID funding a Television and a VCR were being purchased.

The Board of Management was keen, however; they may be limited by their own lack of understanding and knowledge of a resource centre in developing the resource centre to its full potential. There was an additional concept which was considered and this may actually ensure the success of this venture and that is the establishment of a collection of local artefacts. The land on which the school and resource centre stands is owned by a local artist who values traditional art and his son is a teacher at the school. This may be the catalyst required to foster and maintain community interest.

\section{What next?}

At the conclusion of long discussions with the local community, the development of a 5 day workshop informing teachers of Resource Based Learning and the final production of a resource package which will enable other trainers to deliver the workshops, time and dedication of the involved personnel will determine the success of this project. Even though there are no personnel who have teacher librarian qualifications there is a real purpose to this resource centre. Taking teachers, some of whom have never been in a library and think Dewey is one of Donald Duck's nephews, into a future where there are resources in a central building and resource based learning is something that can really happen is the way of the future and is now the challenge facing the trainers of teachers within the Papua New Guinean National Department of Education and the teachers who need to embrace this way of learning.

The workshop was only the beginning and the dream now is to have a resource centre which provides a venue for the local people to use, improve their literacy, and learn how to cook traditional meals, sew clothes for the family and appreciate the culture of which they are so proud.

Does this then change the view that a library is only a collection of books? This therefore is one way of making libraries more meaningful within Papua New Guinea and raising both their importance and their profile. The measurement of success for this resource centre and the community will be to see it vibrant and alive with students young and old. If this resource centre succeeds then it will serve as a model for further development in communities within Papua New Guinea. 


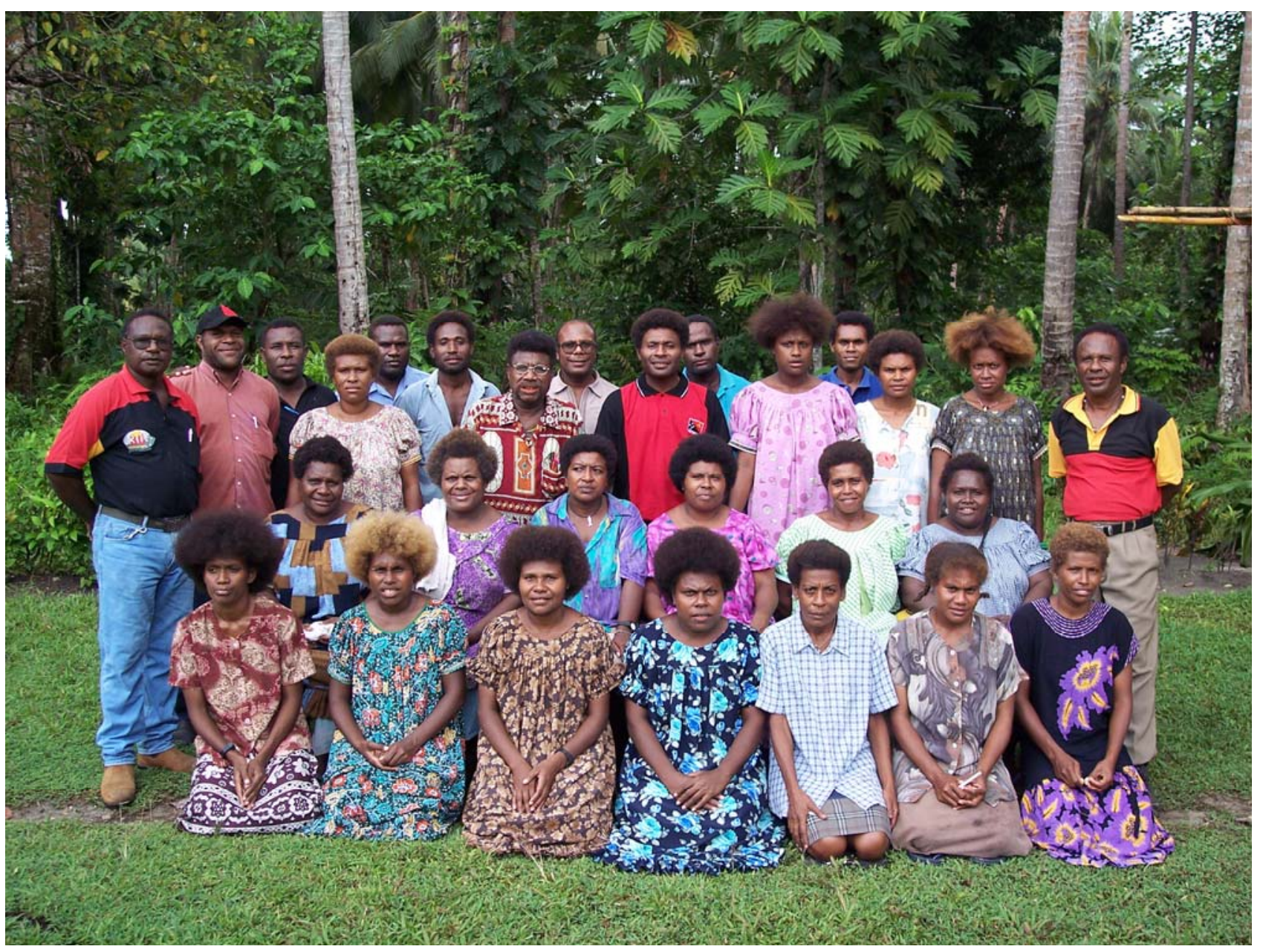

Group Photo - Kaselok Primary School 


\section{References}

Board of Studies NSW 1998 Syllabus: English K-6. Sydney, Board of Studies NSW

Department of Education Tasmania 2004, Tasmanian School Library Guidelines

<http://www.education.tas.gov.au/delic/school-lib-guidelines/>

Education Department of Western Australia 1998, Library Procedures Manual for Automated School Libraries Education Department of Western Australia

Eisenberg, M2004 A Big6 Skills Overview viewed 16 March 2006

<http://www.big6.com/showarticle.php?id=415>

The Information Process

<http://www.edu.pe.ca/bil/bil.asp?ch2.s1.gdtx>

Kuhlthau, C. C. (1985). A process approach to library skills instruction. School Library Media Quarterly, 13/1, 35-40.

Laverty, Cory 2001, Resource Based Learning, last updated 26 Mar 2001, Queen’s University, Ontario, viewed 25 July 2005 < http://stauffer.queensu.ca/inforef/tutorials/rbl/index.htm>

Mitchell, Ian. 1997,Question Dice, Eumemmerring Secondary College, Peel Seeds Issue 37, p.18, March

New South Wales Department of Education (Undated) Information Skills in the School. NSW Department of Education

Nolan, J. P. 1989, A comparison of two methods of instruction in library research skills for elementary school students. Ph.D. Dissertation, Temple University, Philadelphia.

Resnick, L. B. 1987, Education and learning to think. National Academy Press, Washington:

\section{Biographical Notes}

Marlene Filippi, Schools Adviser, International Education Agency, Papua New Guinea: I have presented sessions at the local, state and international level. I have taught in Queensland, New South Wales, and Victoria in Australia and am currently living and working in Papua New Guinea. I have been a classroom teacher, teaching from Kindergarten to Grade 6 in the public system, a teacher librarian and administrator. My qualifications include a Diploma of Education (Primary), Graduate Diploma of Applied Science (Teacher Librarian) and I am currently undertaking a Masters of Applied Science (Teacher Librarian). 
Reproduced with permission of the copyright owner. Further reproduction prohibited without permission. 